\title{
The Genetic Basis of Complex Strabismus
}

\author{
ELIZABETH C. ENGLE \\ Program in Genomics and Department of Neurology, Children's Hospital Boston, Department of Neurology and Division of Neuroscience, \\ Harvard Medical School, Boston, Massachusetts 02115
}

\begin{abstract}
Members of my research laboratory combine clinical, genetic, and molecular biologic approaches to the study of congenital strabismus. Strabismus, which is misalignment of the eyes, affects $2-4 \%$ of the population and causes loss of binocular vision and amblyopia (vision loss in a structurally normal eye). The cause of strabismus when it occurs in the absence of structural brain abnormalities is generally unknown. In the last decade, we have focused our research studies on understanding the genetic etiology of a series of complex strabismus syndromes in which eye movement in at least one direction is limited or paralyzed. We are discovering that these disorders result from mutations in genes necessary for the normal development and connectivity of brainstem ocular motoneurons, including PHOX2A, SALL4, KIF21A, ROBO3, and HOXA1, and we now refer to these syndromes as the "congenital cranial dysinnervation disorders," or CCDD. (Pediatr Res 59: 343-348, 2006)
\end{abstract}

$\mathbf{M}^{\mathrm{s}}$ interest in complex strabismus arose from a clinical encounter I had with a toddler in 1992, during my senior residency year on the Neurology Service at Children's Hospital Boston. This 1-y-old and many of his relatives were born with bilateral ptosis and with both eyes "fixed" in a downward position, requiring them to assume a chin-up head position (1). During the toddler's evaluation, our ophthalmology consultants diagnosed him with a rare Mendelian form of strabismus referred to as "congenital fibrosis of the extraocular muscles" (CFEOM). Having not heard of CFEOM, I searched the literature and learned that this syndrome was one of several complex strabismus syndromes that presented as congenital, nonprogressive ophthalmoplegia (2). Ophthalmologists noted that patients with these syndromes had globes (eyeballs) that were restricted in their movement both when the patient tried to actively move their eyes as well as when a physician tried to passively pull the globe in the direction the patient could not look (positive forced duction testing). These findings, together with the "tight" feel to the extraocular muscles at surgery and presence of connective tissue on

Received September 3, 2005; accepted November 2, 2005.

Correspondence: Elizabeth C. Engle, M.D., Program in Genomics, Enders 560.2, Children's Hospital Boston, 300 Longwood Avenue, Boston, MA 02115; e-mail: elizabeth.engle@childrens.harvard.edu

Supported by National Eye Institute grants EY12498, EY13583, and EY15298.

E.C.E. was the recipient of the Society for Pediatric Research 2005 E. Mead Johnson Award presented at the 2005 Annual Meeting of the Pediatric Academic Societies, Washington, DC.

DOI: $10.1203 / 01 . p d r .0000200797 .91630 .08$ extraocular muscle biopsy, led ophthalmologists to propose that these disorders resulted from primary fibrosis of the extraocular muscles.

In 1992, CFEOM and the related syndromes were clinical diagnoses and their underlying molecular genetic defects were unknown. I wished to learn molecular neurogenetics and I was fortunate that, simultaneous with my clinical introduction to CFEOM and the end of my residency training, short tandem repeat polymorphisms within the genome were discovered. These advances revolutionized genetics and made linkage analysis techniques accessible to clinical fellows such as myself. The congenital and nonprogressive nature of CFEOM, coupled with the large number of affected individuals in my patient's family, made them an ideal pedigree for such analysis.

Over time, my laboratory's focus has expanded from studies of this family's disorder, later named CFEOM1, to encompass the genetics of other complex strabismus syndromes, including other forms of CFEOM, Duane syndrome, horizontal gaze palsy, Möbius syndrome, Brown syndrome, congenital ptosis, and Marcus Gunn syndrome. The neuropathologic findings reported by others in Duane syndrome $(3,4)$ and later by us in CFEOM1 (5) led us to hypothesize that these disorders resulted not from primary extraocular fibrosis but instead from errors in the development of cranial motoneurons. CFEOM1 and several other complex strabismus syndromes are often inherited, and we have taken advantage of continuing advances in positional cloning techniques to explore this hypothesis.

Our approach to defining the genetic defects in complex strabismus typically begins with the ascertainment and clinical characterization of complex strabismus families. This ongoing process benefits from collaborations with clinicians worldwide. After enrollment of study participants, we categorize each participant's and potentially his/her family's phenotype based on the pattern of abnormal eye movements, dividing

Abbreviations: CCDD, congenital cranial dysinnervation disorders; CFEOM, congenital fibrosis of the extraocular muscles; HGPPS, horizontal gaze palsy with progressive scoliosis 
them into those with gaze abnormalities consistent with dysfunction of extraocular muscles innervated by axons from the oculomotor, trochlear, and/or abducens nuclei (Fig. 1 and Fig. $2 a$ ). If appropriate, we then determine whether the family's phenotype maps to candidate genetic loci and/or if the affected individuals harbor mutations in one of the complex strabismus genes we have identified (and describe below). If the pedigree does not map to a known locus and the family is large enough, we may perform a genome-wide linkage screen to define a new complex strabismus locus, followed by positional cloning techniques to identify the mutated gene. Thus far, we have defined multiple complex strabismus genetic loci and identified the five disease genes known to date. Supporting our hypothesis, each of these genes appears to be essential to a specific step in the development of the ocular cranial nuclei and their axonal connectivity. The growing evidence that complex strabismus can, indeed, primarily result from aberrant signaling to the extraocular muscles by neurons in the CNS has led us to name these syndromes "congenital cranial dysinnervation disorders," or CCDD (Fig. 1) (6). In the following paragraphs I will review CCDD syndromes that result from mutations in genes essential for correct axonal targeting of the motor neurons (ROBO3), motor neuron development (HOXA1, PHOX2A, and likely SALL4), and correct axonal targeting of the extraocular muscles (KIF21A).

\section{HGPPS}

Errors in the development of axons targeting abducens neurons. HGPPS (MIM 607313) is a rare autosomal recessive disorder first described in 1970 in consanguineous Greek pedigrees (7; Fig. 2b) and subsequently reported in consanguineous pedigrees of many different ethnicities, as well as in offspring of unrelated parents (8). Affected individuals are born with absent horizontal eye movements and, in addition, develop severe progressive scoliosis starting in infancy or childhood. In 2002, members of Dr. Joanna Jen's laboratory at UCLA mapped a gene for HGPPS to a 30-cM region of chromosome 11 in two pedigrees (9). We had enrolled families with this disorder and found that they, too, mapped to the

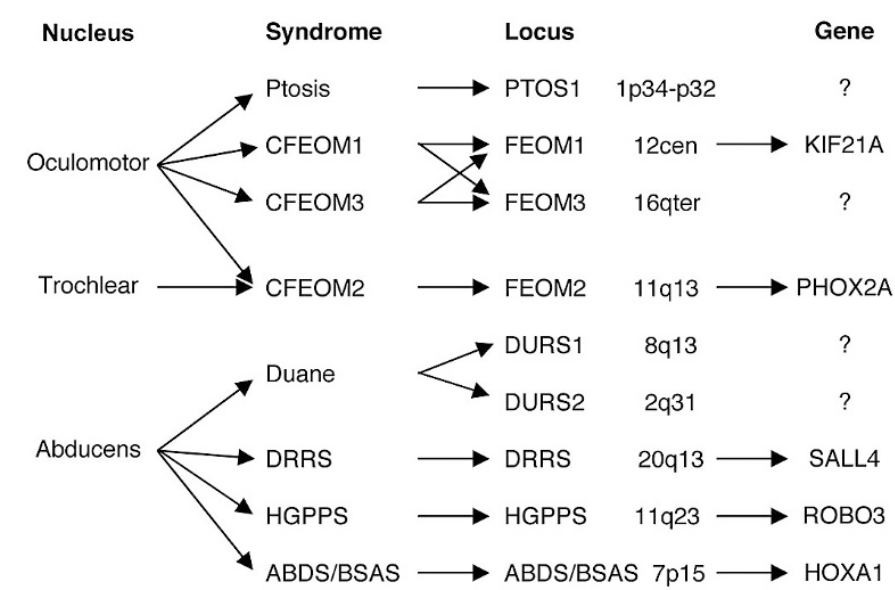

Figure 1. Overview of the ocular CCDD, showing the three ocular nuclei, a subset of the syndromes that can result from their maldevelopment, and each syndrome's corresponding genetic locus and, when identified, the mutated gene. chromosome 11 locus and, in addition, harbored key recombination events that reduced the HGPPS critical region to 2 cM. We collaborated with Dr. Jen to study the HGPPS phenotype and to identify the HGPPS gene.

Similar to previous reports of HGPPS patients (10), magnetic resonance imaging (MRI) of affected individuals from pedigrees linked to the chromosome 11 locus identified hypoplasia of the pons and medulla, with an unusual midline cleft in the medulla. Unexpectedly, electrophysiological studies revealed that the corticospinal and dorsal somatosensory tracts, the major descending and ascending tracts whose axons normally cross the midline in the medulla to reach their contralateral targets in the spinal cord and thalamus, respectively, do not cross the midline in HGPPS patients (11). Absence of these crossing fibers is the likely cause of the midline medullary cleft found by MRI. It is remarkable that HGPPS patients have so few symptoms attributable to the lack of corticospinal and dorsal column-medial lemniscus tract crossing, and it seems likely that these uncrossed axons succeed in finding and innervating their correct targets, albeit on the incorrect side of the body.

Mutation analysis of HGPPS candidate genes in 10 unrelated probands from consanguineous pedigrees revealed homozygous nonsense, frame shift, splice-site, and missense mutations in $\mathrm{ROBO} 3 . \mathrm{ROBO} 3$ is a large gene that encodes a cell adhesion molecule containing five extracellular immunoglobulin-like motifs, three fibronectin-like motifs, a transmembrane domain, and an intracellular tail containing signaling motifs (11). ROBO3 is expressed in the human fetal hindbrain, and the nature and distribution of these mutations suggests that HGPPS results from the complete loss of ROBO3 function (11). Human ROBO3 shares homology with roundabout genes important in axon guidance in developing Drosophila, zebrafish, and mouse. When Robo function is lost in Drosophila or zebrafish, however, axons cross and re-cross the midline aberrantly, the opposite of the HGPPS phenotype (12). Human ROBO3 is most homologous to mouse Robo3 (Rigl), and when members of Dr. Tessier-Lavigne's lab at UCSF removed Robo3 function in mouse and looked at the spinal cord, they found complete failure of spinal commissural axons to cross the midline (13). Subsequently, their collaborators studied the Robo $^{-1}{ }^{-1}$ mouse brainstem and noted complete failure of midline crossing by hindbrain precerebellar axons and neurons (14), similar to what we predict in HGPPS patients. In contrast to HGPPS, the Robo $3^{--}$mice die at birth (13). In general, however, the conservation of ROBO3 structure and function between humans and mouse should permit use of the mouse to model at least some aspects of the HGPPS phenotype.

Scoliosis is a relatively common disability, with an estimated incidence of $4-15.7 \%$ in the school-aged population (15), and the finding that $\mathrm{ROBO} 3$ mutations result in scoliosis supports a neurogenic cause for this disorder. Future studies should determine whether scoliosis occurs secondary to lack of midline crossing of descending long tracts and how these long tracts find ipsilateral targets. Our MR imaging revealed normal bilateral presence of the abducens axons exiting the brainstem and normal orbital extraocular muscle configuration and size (11), suggesting that the horizontal gaze palsy results 
a

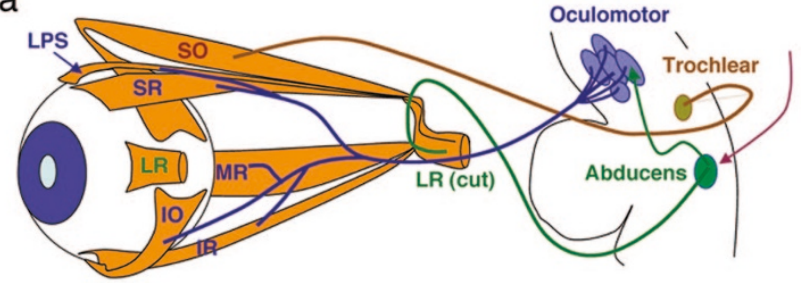

C

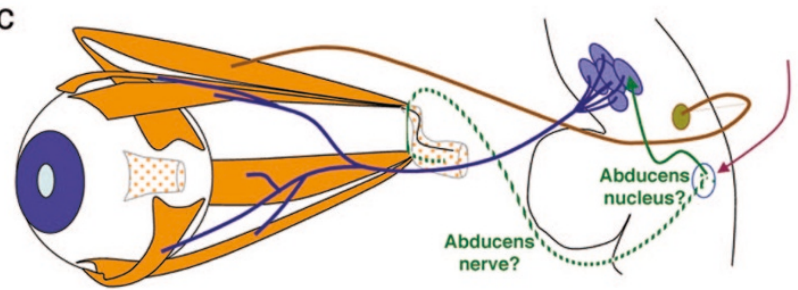

e

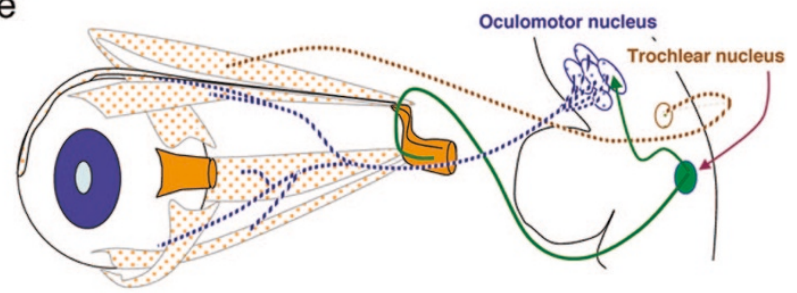

g

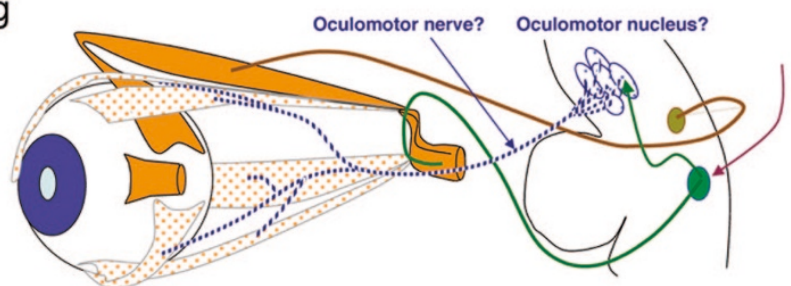

b

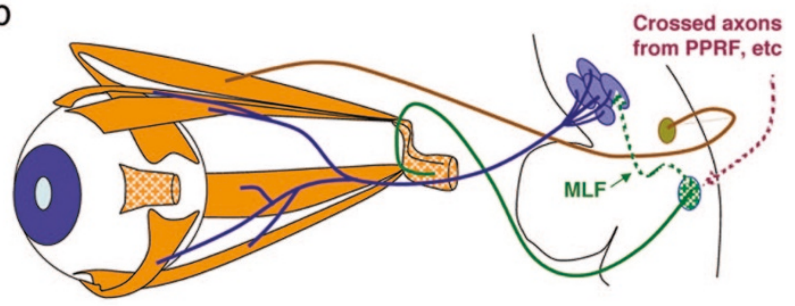

d

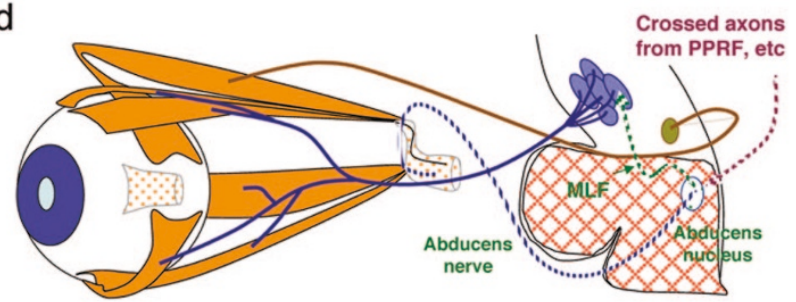

f

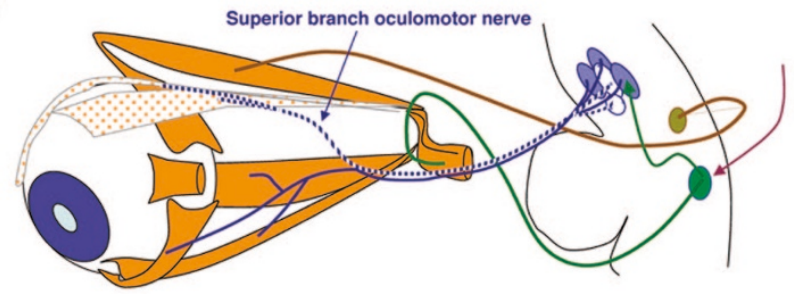

h

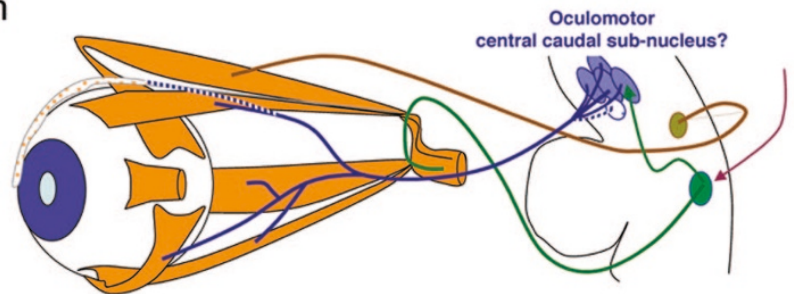

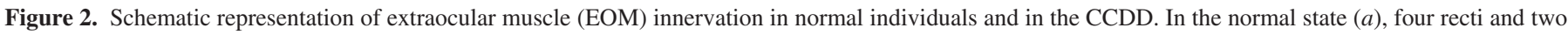

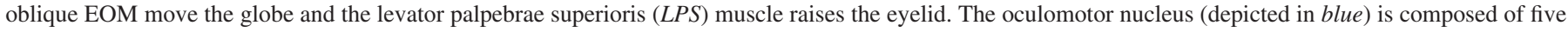

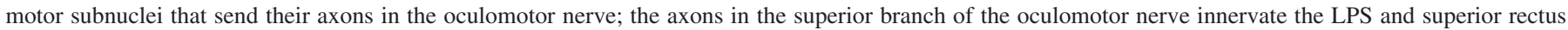

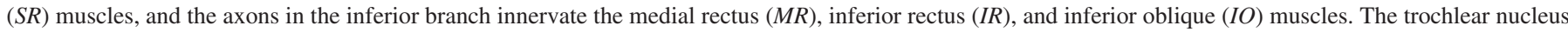

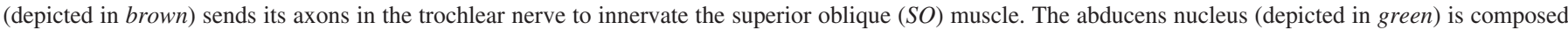

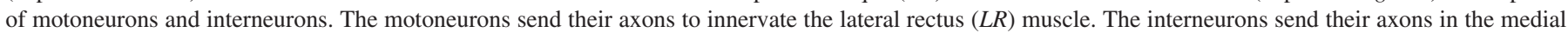

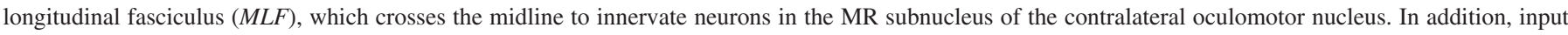

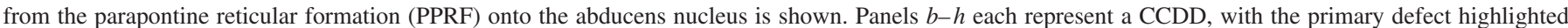

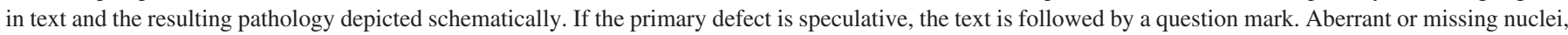

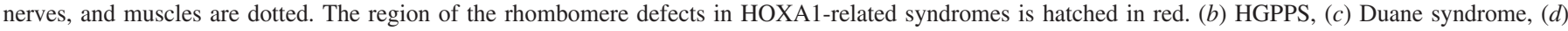
HOXA1-related syndromes, $(e)$ CFEOM2, $(f)$ CFEOM1, $(g)$ CFEOM3, $(h)$ congenital ptosis.

from failure of axons extending from developing neurons in the medial longitudinal fasciculus and paramedian reticular formation pathways to cross the midline and appropriately innervate neurons in the abducens nucleus (Fig. 2b). Future studies should help determine which of these abducens-related tracts and/or neurons require $\mathrm{ROBO} 3$ function.

\section{THE HUMAN HOXA1-RELATED SYNDROMES: BOSLEY-SALIH-ALORAINY SYNDROME AND ATHABASCAN BRAINSTEM DYSGENESIS SYNDROME}

Absent abducens nuclear development secondary to aberrant hindbrain segmentation. Recently, our collaborators in Saudi Arabia recognized a new recessive CCDD syndrome that we named Bosley-Salih-Alorainy syndrome (BSAS) in their honor (16; Fig. $2 d$ ). The syndrome was recognized in offspring of consanguineous parents. Affected children have bilateral Duane syndrome, a congenital horizontal eye movement disorder with limited abduction and narrowing of the palpebral fissure on attempted adduction. Isolated Duane syndrome is the most common CCDD, and autopsy studies of individuals with Duane syndrome have found absence of the abducens motoneurons and cranial nerve, with sparing of the abducens interneurons that send their axons through the medial longitudinal fasciculus to the oculomotor nucleus (Fig. $2 c$ ) $(3,4)$. In contrast to isolated Duane syndrome, most patients with BSAS also have congenital sensorineural deafness secondary to bilateral absence of the cochlea, semicircular 
canals, and vestibule (common cavity deformity). Further evaluation of these patients revealed variable malformations of the internal carotid arteries, ranging from unilateral hypoplasia to bilateral agenesis. Subsets of BSAS patients also have delayed motor milestones and autism spectrum disorder (ASD). Once recognized as a syndrome, we reviewed our database and found that we had previously ascertained a Turkish patient from a consanguineous family who also had the BSAS phenotype.

As we were working together to characterize these patients, we noted that this new syndrome actually overlapped with another recessive syndrome reported in consanguineous pedigrees-the Athabascan brainstem dysgenesis syndrome (ABDS; OMIM \#601536) described in Native American children (17). Similar to BSAS, ABDS children were reported to have horizontal gaze restriction, sensorineural deafness, and delayed motor development (17), and retrospective review of MR images revealed previously undiagnosed internal carotid artery anomalies. In addition, however, ABDS children have central hypoventilation, mental retardation, and subsets have facial weakness, vocal cord paralysis, and conotruncal heart defects, including tetralogy of Fallot and double aortic arch (17).

We conducted a genome-wide linkage screen and mapped BSAS to the region of chromosome 7 encompassing the HOXA gene cluster. This was very exciting because the phenotypes reported in the two Hoxal ${ }^{-/}$mouse models are remarkably similar to the BSAS and ABDS syndromes. The mice have grossly abnormal rhombomere segmentation with errors in neural patterning of the hindbrain and associated ganglia (18-20), resulting in aberrant abducens and inner ear development. Hoxal ${ }^{-/-}$mice die soon after birth, and a subset of them die from hypoventilation. We screened HOXAl for disease-causing mutations, and affected individuals from each of the three founder populations (Saudi, Turkish, and Native American) were found to harbor a unique homozygous truncating HOXAl mutation that is predicted to result in complete loss of HOXAl function (16). Hence, this new CCDD results from a more diffuse error in hindbrain segmentation (Fig. $2 d$ ).

To the best of our knowledge, this is the first description of viable homozygous mutations in any human HOX gene and the first syndromes resulting from mutations in a $H O X$ gene critical for CNS development. The phenotypic variability between BSAS and ABDS could result from differences in genetic background or environment between these isolated founder populations. The vascular patterning defects of the internal carotid arteries and cardiac outflow tracts have not been reported in $\mathrm{Hoxal}^{--}$mice, and may represent a new function for this gene in humans. Finally, it is particularly intriguing that individuals with loss of HOXAl function can be autistic or mentally retarded. Given that forebrain and cerebellar defects have not been reported in $\mathrm{Hoxal}^{--}$mice and Hoxal expression has not been detected above the brainstem, this suggests that brainstem dysgenesis may lead to higher cortical dysfunction.

\section{CFEOM2}

Failure of oculomotor and trochlear motoneuron development. We classify a CCDD phenotype as CFEOM based on the presence of congenital eye movement disorder that pri- marily affects function of the extraocular muscles in the oculomotor nerve distribution (Fig. 2e). We then subclassify CFEOM cases as CFEOM1, CFEOM2, or CFEOM3 based on specific phenotypic features. As we learn more about CFEOM genetics, we are also able to classify an individual or pedigree by their genetic mutation or family linkage data. We have defined three CFEOM genetic loci (FEOM1, FEOM2, FEOM3), and identified KIF21A and PHOX2A as the FEOM1 and FEOM2 genes, respectively. There is a correlation between CFEOM phenotype and genotype, such that most individuals with CFEOM1 harbor KIF21A mutations, most individuals with CFEOM2 harbor PHOX2A mutations, and most large pedigrees with CFEOM3 map to the FEOM3 locus (a locus for which the disease gene is not yet identified). We have, however, found exceptions to these genotype-phenotype correlations (21-23).

CFEOM2 (MIM 602078) was first recognized in consanguineous Saudi Arabian pedigrees. Affected individuals with this recessive phenotype are born with bilateral ptosis with their eyes primarily fixed in an exotropic position, with or without secondary hypertropia or hypotropia $(24-26)$. This eye position suggests that the only normally functioning extraocular muscle is the abducens-innervated lateral rectus, which succeeds in pulling each eye outward (Fig. 2e). To determine the genetic cause of this CCDD, we conducted a genome-wide linkage screen and mapped CFEOM2 to chromosome 11q13, referred to as the FEOM2 locus (26). We constructed a physical map across the FEOM2 region and screened candidate genes within it (27). Nine genes were analyzed before mapping and identifying mutations in $A R I X$, renamed $P H O X 2 A$ to parallel published work in other species. PHOX2A is composed of three exons and encodes a homeodomain transcription factor protein. We initially identified three distinct mutations, two predicted to disrupt splicing and one that alters an amino acid within the conserved brachyurylike domain (27). Subsequently, collaborative work led to the identification of a homozygous nonsense mutation in the coding region of $P H O X 2 A$ in an Iranian pedigree with CFEOM2 (28). This nonsense mutation provided strong evidence that the human CFEOM2 phenotype results from a complete loss of function of $P H O X 2 A$.

Phox $2 a$ and its close relative, Phox $2 b$, are paired-like transcription factor genes with identical homeodomains and expression patterns restricted to several classes of differentiating neurons in the central and peripheral nervous system $(29,30)$. Mouse Phox $2 a^{--}$null mutants (31) and homozygous soulless zebrafish with point mutations in the Phox $2 a$ homeodomain (32) die soon after birth. These animals also have absence of the locus coeruleus (LC), atrophy of cranial sensory ganglia, and, in the mouse, absence of parasympathetic ganglia of the head (31), phenotypes that we do not detect in CFEOM2 patients. In both mutants, the oculomotor and trochlear nuclei are also absent $(32,33)$, consistent with Phox2a expression at E9 in the proliferating oculomotor and trochlear motoneuron precursors (30). These findings support our hypothesis that CFEOM2 results from the abnormal development of the oculomotor and trochlear nuclei (Fig. 2e). 


\section{CFEOM1}

\section{Aberrant axonal targeting of the extraocular muscles by a} branch of the oculomotor nerve. The CFEOM1 phenotype (MIM135700) was described in the medical literature as early as 1840 (34) and, unlike the three syndromes described above, CFEOM1 segregates as an autosomal dominant trait and new cases seem to arise with steady frequency worldwide (Fig. 2f). An individual with CFEOM1 is born with congenital nonprogressive bilateral external ophthalmoplegia and congenital bilateral ptosis (note, the pupils are spared and thus there is not an "internal ophthalmoplegia"). The primary position of both eyes must be downward (infraducted) and $\mathrm{s} / \mathrm{he}$ must be unable to raise either eye above the horizontal midline. We refer to a family as a "CFEOM1 pedigree" when CFEOM1 is transmitted in the family as a fully penetrant, autosomal dominant trait, and all affected individuals in the family meet the CFEOM1 diagnostic criteria.

CFEOM1 is the diagnosis given to the toddler I cared for on the Neurology Service in 1992. Using radioactive linkage, we mapped the CFEOM1 phenotype in his family to the centromeric region of chromosome 12 (1), which is now referred to as the FEOM1 locus. Over time, we enrolled many additional families with CFEOM1 and refined the FEOM1 critical region to $3 \mathrm{cM}$, still spanning the centromere of chromosome 12 $(21,35)$. Before identifying the FEOM1 gene, we were able to conduct a postmortem neuropathologic examination of an elderly affected member of the original CFEOM1 pedigree, who died of unrelated causes. The primary abnormality we found was absence of the superior division of the oculomotor nerve (cnIII) and the corresponding motoneurons in the midbrain oculomotor nucleus, and marked abnormalities of the levator palpebrae superioris and superior rectus muscles, which are normally innervated by this branch and elevate the eyelid and the globe, respectively (5) (Fig. 2f). These pathologic findings have now been confirmed by high-resolution MR images of the brainstem and orbit of individuals with CFEOM1 (36) and suggest that the FEOM1 gene was essential to the development of this branch of the oculomotor nerve, and is likely important to axonal targeting of the extraocular muscles.

In 2000, the release of human genomic sequence by the Genome Project combined with increasing public availability of powerful computer programs for mining genomic sequence made it feasible for us to begin mutation analysis of candidate genes within the FEOM1 region, which had been technically more difficult given its location adjacent to the centromere. After screening a series of normal genes, we found that individuals with CFEOM1 harbor heterozygous mutations in a developmental kinesin, KIF21A (37). Kinesins are molecular motors that interact with and transport cargo along microtubules. There are at least 45 human kinesins, each transporting specific cargos such as mitochondria, vesicles, and protein complexes. Although human KIF21A had not been previously recognized, mouse Kif21a had been shown to be a developmental kinesin expressed primarily in the CNS, and to be engaged in anterograde axonal transport (38).
$\mathrm{KIF} 21 \mathrm{~A}$ is predicted to be similar in structure to classical kinesin and to contain three domains-motor, stalk, and tail (38). The motor domain interacts with the microtubule track, and two motor domains from interacting kinesins may "walk" together down the microtubule. The tail domain typically carries the cargo. The long flexible stalk domain links the motor and tail domains, and contains coiled-coil regions where two kinesins may interact, resulting in homo- or heterodimerization. KIF21A's cargo and potential interacting proteins are not yet known.

We have identified KIF21A mutations in the vast majority of CFEOM1 patients we have screened (37). Interestingly, despite the large size of KIF2IA - the gene contains 38 exons and encodes a 1674 amino acid protein-we have identified only seven different pathogenic mutations $(37,39)$. All seven are missense mutations and several alter the same or adjacent nucleotides, resulting in only four amino acid residue substitutions. Three of the altered amino acid residues are located within a single coiled-coil region of the KIF21A stalk, and the fourth is at the end of the motor domain adjacent to the stalk. We hypothesize that these recurrent, specific KIF21A mutations may interfere with dimerization of KIF21A to itself or another binding partner, or possibly interfere with the ability of KIF21A to move into and out of an active state. Disruption of either of these processes could render KIF21A unable to deliver its unidentified cargo from the oculomotor motoneurons to the synapse of the developing neuromuscular junction of the extraocular muscle.

\section{CONCLUSION}

The identification and genetic analysis of rare disorders of complex strabismus has led to the identification of a series of disparate genes, each of which plays an essential role in the normal development and/or connectivity of cranial motoneurons. Some effect development of the midbrain oculomotor and/or trochlear nuclei and result in primary abnormalities of vertical gaze, whereas others effect development of the pontine abducens nucleus and result in primary abnormality of horizontal gaze. The underlying gene defects lead to errors at various locations along the developing neuro-axis, including errors in axonal targeting onto the motoneurons, errors in motoneuron development, and errors in axonal targeting onto the extraocular muscles. We anticipate that continued studies of each gene's role in neurodevelopment would provide additional knowledge about the pathogenesis of oculomotor disease and the development of the human brainstem.

Acknowledgments. I am deeply grateful and indebted to all the past and present members of my laboratory and our many collaborators. I also wish to thank the many mentors who have guided me, the National Eye Institute and the private foundations that have funded me, and my family who always supports me.

\section{REFERENCES}

1. Engle EC, Kunkel LM, Specht LA, Beggs AH 1994 Mapping a gene for congenital fibrosis of the extraocular muscles to the centromeric region of chromosome 12. Nat Genet 7:69-73 
2. Brown HW 1950 Congenital structural muscle anomalies. In: Allen JH (ed) Strabismus Ophthalmic Symposium. CV Mosby Co., St. Louis, pp 205-236

3. Hotchkiss MG, Miller NR, Clark AW, Green WR 1980 Bilateral Duane's retraction syndrome: a clinical-pathological case report. Arch Ophthalmol 98:870-874

4. Miller NR, Kiel SM, Green WR, Clark AW 1982 Unilateral Duane's retraction syndrome (type 1). Arch Ophthalmol 100:1468-1472

5. Engle EC, Goumnerov BC, McKeown CA, Schatz M, Johns DR, Porter JD, Beggs AH 1997 Oculomotor nerve and muscle abnormalities in congenital fibrosis of the extraocular muscles. Ann Neurol 41:314-325

6. Gutowski NJ, Bosley TM, Engle EC 2003 110th ENMC International Workshop: the congenital cranial dysinnervation disorders (CCDDs). Naarden, The Netherlands, 25-27 October, 2002. Neuromuscul Disord 13:573-578

7. Dretakis EK 1970 Familial idiopathic scoliosis associated with congenital encephalopathy in three children of the same family. Acta Orthop Traumatol Hell 22:51-55

8. Chan WM, Traboulsi E, Arthur B, Friedman N, Andrews C, Engle E 2005 Horizontal gaze palsy with progressive scoliosis can result from compound heterozygous mutations in ROBO3. J Med Genet (in press)

9. Jen J, Coulin CJ, Bosley TM, Salih MA, Sabatti C, Nelson SF, Baloh RW 2002 Familial horizontal gaze palsy with progressive scoliosis maps to chromosome 11q23-25. Neurology 59:432-435

10. Pieh C, Lengyel D, Neff A, Fretz C, Gottlob I 2002 Brainstem hypoplasia in familial horizontal gaze palsy and scoliosis. Neurology 59:462-463

11. Jen JC, Chan WM, Bosley TM, Wan J, Carr JR, Rub U, Shattuck D, Salamon G, Kudo LC, Ou J, Lin DD, Salih MA, Kansu T, Al Dhalaan H, Al Zayed Z, MacDonald DB, Stigsby B, Plaitakis A, Dretakis EK, Gottlob I, Pieh C, Traboulsi EI, Wang Q, Wang L, Andrews C, Yamada K, Demer JL, Karim S, Alger JR, Geschwind DH, Deller T, Sicotte NL, Nelson SF, Baloh RW, Engle EC 2004 Mutations in a human ROBO gene disrupt hindbrain axon pathway crossing and morphogenesis. Science 304:1509-1513

12. Seeger M, Tear G, Ferres-Marco D, Goodman CS 1993 Mutations affecting growth cone guidance in Drosophila: genes necessary for guidance toward or away from the midline. Neuron 10:409-426

13. Sabatier C, Plump AS, Le Ma Brose K, Tamada A, Murakami F, Lee EY, Tessier-Lavigne M 2004 The divergent Robo family protein rig-1/Robo3 is a negative regulator of slit responsiveness required for midline crossing by commissural axons. Cell 117:157-169

14. Marillat V, Sabatier C, Failli V, Matsunaga E, Sotelo C, Tessier-Lavigne M, Chedotal A 2004 The slit receptor Rig-1/Robo3 controls midline crossing by hindbrain precerebellar neurons and axons. Neuron 43:69-79

15. Weinstein SL, Dolan LA, Spratt KF, Peterson KK, Spoonamore MJ, Ponseti IV 2003 Health and function of patients with untreated idiopathic scoliosis: a 50-year natural history study. JAMA 289:559-567

16. Tischfield M, Bosley TM, Salih MA, Alorainy I, Sener EC, Nester MJ, Oystreck DT, Chan WM, Andrews C, Erickson RP, Engle EC 2005 Homozygous HOXA1 mutations disrupt human brainstem, inner ear, cardiovascular, and cognitive development. Nat Genet 37:1035-1037

17. Holve S, Friedman B, Hoyme HE, Tarby TJ, Johnstone SJ, Erickson RP, Clericuzio CL, Cunniff C 2003 Athabascan brainstem dysgenesis syndrome. Am J Med Genet A $120: 169-173$

18. Lufkin T, Dierich A, LeMeur M, Mark M, Chambon P 1991 Disruption of the Hox-1.6 homeobox gene results in defects in a region corresponding to its rostral domain of expression. Cell 66:1105-1119

19. Chisaka O, Musci TS, Capecchi MR 1992 Developmental defects of the ear, cranial nerves and hindbrain resulting from targeted disruption of the mouse homeobox gene Hox-1.6. Nature 355:516-520

20. Mark M, Lufkin T, Vonesch JL, Ruberte E, Olivo JC, Dolle P, Gorry P, Lumsden A, Chambon P 1993 Two rhombomeres are altered in Hoxa-1 mutant mice. Development 119:319-338

21. Engle EC, McIntosh N, Yamada K, Lee BA, Johnson R, O'Keefe M, Letson R, London A, Ballard E, Ruttum M, Matsumoto N, Saito N, Collins ML, Morris L, Del Monte M, Magli A, de Berardinis T 2002 CFEOM1, the classic familial form of congenital fibrosis of the extraocular muscles, is genetically heterogeneous but does not result from mutations in ARIX. BMC Genet 3:3

22. Traboulsi EI, Lee BA, Mousawi A, Khamis AR, Engle EC 2000 Evidence of genetic heterogeneity in autosomal recessive congenital fibrosis of the extraocular muscles. Am J Ophthalmol 129:658-662
23. Yamada K, Chan WM, Andrews C, Bosley TM, Sener EC, Zwaan JT, Mullaney PB, Ozturk BT, Akarsu AN, Sabol LJ, Demer JL, Sullivan TJ, Gottlob I, Roggenkaemper P, Mackey DA, De Uzcategui CE, Uzcategui N, Ben-Zeev B, Traboulsi EI, Magli A, De Berardinis T, Gagliardi V, Awasthi-Patney S, Vogel MC, Rizzo JF 3rd, Engle EC 2004 Identification of KIF21A mutations as a rare cause of congenital fibrosis of the extraocular muscles type 3 (CFEOM3). Invest Ophthalmol Vis Sci 45:2218-2223

24. Traboulsi E, Jaafar M, Kattan H, Parks M 1993 Congenital fibrosis of the extraocular muscles: Report of 24 cases illustrating the clinical spectrum and surgical management. Am Orthopt J 43:45-53

25. Assaf A 1997 Bilateral congenital vertical gaze disorders: congenital muscle fibrosis or congenital central nervous abnormalities. Neuroophthalmology 17:23-30

26. Wang SM, Zwaan J, Mullaney PB, Jabak MH, Al-Awad A, Beggs AH, Engle EC 1998 Congenital fibrosis of the extraocular muscles type 2, an inherited exotropic strabismus fixus, maps to distal 11q13. Am J Hum Genet 63:517-525

27. Nakano M, Yamada K, Fain J, Sener EC, Selleck CJ, Awad AH, Zwaan J, Mullaney PB, Bosley TM, Engle EC 2001 Homozygous mutations in ARIX(PHOX2A) result in congenital fibrosis of the extraocular muscles type 2. Nat Genet 29:315-320

28. Yazdani A, Chung DC, Abbaszadegan MR, Al-Khayer K, Chan WM, Yazdani M, Ghodsi K, Engle EC, Traboulsi EI 2003 A novel PHOX2A/ARIX mutation in an Iranian family with congenital fibrosis of extraocular muscles type 2 (CFEOM2). Am J Ophthalmol 136:861-865

29. Tiveron MC, Hirsch MR, Brunet JF 1996 The expression pattern of the transcription factor Phox 2 delineates synaptic pathways of the autonomic nervous system. J Neurosci 16:7649-7660

30. Pattyn A, Morin X, Cremer H, Goridis C, Brunet JF 1997 Expression and interactions of the two closely related homeobox genes Phox $2 \mathrm{a}$ and Phox $2 \mathrm{~b}$ during neurogenesis. Development 124:4065-4075

31. Morin X, Cremer H, Hirsch MR, Kapur RP, Goridis C, Brunet JF 1997 Defects in sensory and autonomic ganglia and absence of locus coeruleus in mice deficient for the homeobox gene Phox2a. Neuron 18:411-423

32. Guo S, Brush J, Teraoka H, Goddard A, Wilson SW, Mullins MC, Rosenthal A 1999 Development of noradrenergic neurons in the zebrafish hindbrain requires BMP, FGF8, and the homeodomain protein soulless/Phox2a. Neuron 24:555-566

33. Pattyn A, Morin X, Cremer H, Goridis C, Brunet JF 1999 The homeobox gene Phox $2 b$ is essential for the development of autonomic neural crest derivatives. Nature 399:366-370

34. Baumgarten M 1840 Erfahrungen uber den strabismus und die Muskeldurchschneidung am Auge in physiologischpathologischer und therapeutischer Beziehung. Monatsschr Med Augenheilkd Chir 3:474-499

35. Engle EC, Marondel I, Houtman WA, de Vries B, Loewenstein A, Lazar M, Ward DC, Kucherlapati R, Beggs AH 1995 Congenital fibrosis of the extraocular muscles (autosomal dominant congenital external ophthalmoplegia): genetic homogeneity, linkage refinement, and physical mapping on chromosome 12. Am J Hum Genet 57:1086-1094

36. Demer JL, Clark RA, Engle EC 2005 Magnetic resonance imaging evidence for widespread orbital dysinnervation in congenital fibrosis of extraocular muscles due to mutations in KIF21A. Invest Ophthalmol Vis Sci 46:530-539

37. Yamada K, Andrews C, Chan WM, McKeown CA, Magli A, De Berardinis T, Loewenstein A, Lazar M, O'Keefe M, Letson R, London A, Ruttum M, Matsumoto N, Saito N, Morris L, Monte M, Johnson RH, Uyama E, Houtman WA, De Vries B, Carlow TJ, Hart BL, Krawiecki N, Shoffner J, Vogel MC, Katowitz J, Goldstein SM, Levin AV, Sener EC, Ozturk BT, Akarsu AN, Brodsky MC, Hanisch F, Cruse RP, Zubcov AA, Robb RM, Roggenkaemper P, Gottlob I, Kowal L, Battu R, Trabouls EI, Franceschini P, Newlin A, Demer JL, Engle EC 2003 Heterozygous mutations of the kinesin KIF21A in congenital fibrosis of the extraocular muscles type 1 (CFEOM1). Nat Genet 35:318-321

38. Marszalek JR, Weiner JA, Farlow SJ, Chun J, Goldstein LS 1999 Novel dendritic kinesin sorting identified by different process targeting of two related kinesins: KIF21A and KIF21B. J Cell Biol 145:469-479

39. Yamada K, Hunter DG, Andrews C, Engle E 2005 A novel KIF21A mutation in a patient with congenital fibrosis of the extraocular muscles and Marcus Gunn jaw winking phenomenon. Arch Ophthalmol 123:1254-1259 